\title{
Going It Alone: Developing An Independent Study Abroad Program
}

Rusty L. Juban, (Email: rjuban@ @elu.edu), Southeastern Louisiana University Aristides R. Baraya, (Email: abaraya@ selu.edu), Southeastern Louisiana University Michael Craig Budden, (Email: mbudden@ selu.edu), Southeastern Louisiana University

\begin{abstract}
With a greater focus on internationalization, today's business students are encouraged to participate in study abroad programs. For smaller, regional business programs seeking a quality study abroad program, faculty and administrators may view "piggybacking" onto existing programs of larger universities as their only viable option. However, piggyback participation in external programs may require that a university forsake its own standards and objectives, and accept the objectives of other study abroad programs. Building on the experiences of one university's study abroad program for MBAs, the idea that piggybacking onto other schools is the only means of creating a high quality international experience for students is rejected.
\end{abstract}

\section{INTRODUCTION}

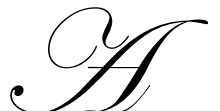

common perception of North Americans, and in particular of U. S. citizens, is that they are ethnocentric and in general resist efforts to internationalize. However, understanding global strategies, international relations and multicultural encounters are essential to a university education. Altbach (2002) discussed the need for American universities to develop programs and activities aimed at providing an international and cross-cultural perspective. Altbach did not see internationalization of business programs as an option, but rather as a necessity. Since many universities reject ethnocentricity and want to broaden their students' horizons, a determination needs to be made as whether to encourage students to participate in other universities' programs or whether a university should create and promote its own program. It is the authors' contention that internally created programs best address the needs of students and faculty, and serves best at furthering the goals of the college.

Many scholars view study abroad to be of special importance in today's global market environment. Why study abroad versus courses taught in a traditional classroom? In their research on knowledge transfer, Whetten and Clark (1996) discussed the impact of lecture-based courses versus experiential courses. Conceptual knowledge is an important component in the understanding of basic concepts presented in introductory courses. However, it does not contribute significantly to the understanding of the dynamic nature of business, especially as such relates to the international arena. Nadkarni (2003), whose research focused on the dynamic nature of business knowledge, felt strongly about the application of business concepts in real situations.

Research has shown that the method of education delivery varies with the circumstances and the goals of a program. While, the best method of delivery has been debated, Brookfield (1984) felt that the best instructional style depends on a variety of factors. One of the factors important for the transfer of business knowledge is the maturity of the learner. For adult learners, the best approaches to education are proactive in nature (Nadkarni, 2003). Knowles (1984) classified adult learning as being either andragogical, more self-directed, or pedagogical, more teacher driven. Needless to say, Knowles felt that andragogical methods worked best with more mature learners. Mature learners prefer greater power over and increased control of the learning process, thus the need for andragogical learning methods in graduate business programs. Again, study abroad opportunities incorporate andragogical methods in the 
delivery of knowledge. It is apparent to the authors that such situations involve those that can best be addressed through personal interaction and involvement - a situation that study abroad provides and through which communication skills are improved.

Two points are clear. First, students learn best when curricula include teaching methods that allow for a match in student learning styles. Second, adult learners will learn better when they are allowed to be more actively involved in the search for knowledge. In recent years, there seems to be a movement toward experiential learning exercises, since experiential courses are proactive and self-directed. Experiential courses build upon information learned in foundation courses and require students to engage in action-oriented tasks designed to help them through their own individual learning experience (Hopkins, 1999). Study abroad programs are an excellent example of experiential learning.

\section{THE PROBLEM}

Study abroad programs come in a variety of forms including: direct enrollment, indirect enrollment, and transnational course-based programs. Direct enrollment courses are internally created programs that involve college faculty and students traveling to a selected country. While in that "host" country, the group can be exposed to culture and business practices through tours, seminars and/or business and university lectures. The experiences gained through direct enrollment courses can be tailored to the objectives of students, faculty, administrators and university study abroad coordinators. While internally created programs have been the standard for most large state universities, the trend for schools with fewer resources was to offer courses through programs established at other universities (indirect enrollment) or a consortium of universities or organizations in a variety of countries (transnational coursebased programs).

Many indirect programs and transnational course-based programs coordinate efforts between schools and provide students opportunities to take courses in different locations. For instance, the American Institute for Foreign Study (AIFS) organizes programs for approximately 40,000 students annually. These programs allow students to "pick and choose" the program that is right for them depending on experience and costs. European Study Abroad (EUSA) focuses on internships in Europe and operates study abroad programs in several countries including Belgium, France, Ireland, Italy, Spain and the United Kingdom. Programs such as EUSA contract with North American universities to meet the high demand of American students interested in internships abroad.

While externally created programs are popular with students, these programs create problems for regional universities and smaller colleges. First, from a faculty governance point of view, there is little if any input into external program design by the faculty of colleges contributing students. The university is usually forced to accept the program as is from the university delivering the program. Content, delivery methods, emphasis on cross-cultural communication and understanding, and associated materials are decided by others with their needs in mind. If a program is not geared to the needs of one's students, one accepts credit for pursuits that potentially do not fit one's goal of providing a relevant international experience that encourages inter-cultural communication and understanding.

Second, programs run through external institutions may detract from a sense of community within a university and college. A cornerstone of graduate business programs is the emphasis on group learning. When students returned from travel abroad, there might be no one to share and build upon their unique experience. In addition, students returning from externally sponsored programs may feel that their educational program was of lower quality because their institution had not committed the resources to develop their own study abroad program.

Third, externally produced, study abroad programs produce no student credit hours for the college and draw tuition dollars to other universities. For several years, Southeastern's encouraged student participation in other universities' programs since none existed locally. Participation reduced our college's student credit hour production since credits earned elsewhere transferred. This acceptance of external credits encouraged out-migration of students and a reduction in credit hour production. Students leaving the home campus and participating in the programs of others negatively impact the budget and support driven by student credit hour production. Out migration of students 
and reductions in student credit hour production were seen as major problems, but they were not the only concern of the program's developers.

Finally, outsourcing study abroad programs did not advance the internationalization of the faculty and campus. To develop students capable of working effectively in a global environment, faculty members need to be globally aware. Sponsoring a self-supporting study abroad program has been a boon to the understanding of Latin America by our faculty. In the last three years, seven faculty members accompanied study abroad students to Costa Rica. Last year, three faculty members were instructors of record for the program. As a consequence, faculty members are becoming more globally aware and culturally confident which translates to higher quality international education for a larger number of students.

Thus, the establishment of a homegrown study abroad program was deemed to have benefits for faculty and students. Faculty members designed the program to suit the communication and cultural awareness needs of students with the expectation that the program meet high quality standards. The program generates student credit hour production and summer tuition funds. The program provides learning and development opportunities for both faculty and students. The benefits of a locally prepared and managed program outweighed the benefits of piggybacking on someone else's program.

\section{AVOIDING THE PIGGYBACK - ESTABLISHING A RELATIONSHIP}

In order for a regional university to develop a quality study abroad program, it requires support from within the institution and assistance from outside partners. The first steps taken by the College of Business and Technology involved soliciting support from administrators for a study abroad program. After presenting the advantages of study abroad to the campus community, the University's administration was supportive of developing in-house programs that would address the needs of students and faculty. The University's administration established an International Initiatives Office that coordinates study abroad and assures quality consistency among the programs. To facilitate greater internationalization within the curricula, the College of Business developed a Latin American Business and Development Initiative charged with creating quality study abroad opportunities in Latin America. Other partners contributed financial support to the program. As a direct show of support, the SGA appropriated $\$ 40,000$ in scholarship funds. The SGA funds were awarded in increments of either $\$ 800$ or $\$ 1250$, depending on student GPAs. In year two of the study abroad program, ninety percent of students received scholarships of at least $\$ 800$. These scholarships made the cost of program affordable to the majority of those who desired to participate. External partners were also called upon to aid the financial backing of the program. An endowment gift $(\$ 100,000)$ was earmarked for support of international programs in the college. Earnings from this endowment are used to supplement scholarship funds for participating students - resulting in four additional students receiving scholarships this year that were not eligible for SGA funding. Still another supporter established an endowment to support Latin American initiatives in the college.

International program partners were found in the developing country of Costa Rica. During an address at Southeastern Louisiana University's campus. Mr. Enrique Iglesias, President of the Inter-American Development Bank, emphasized the importance of Latin America to the southern United States. Due to Southeastern's location, the large number of Hispanics in Louisiana, a desire to establish a program in a country that was stable, had a strong and varied economic climate, beautiful geography, and friendly people, Costa Rica was selected as an ideal location for study abroad. Beginning with members of the chamber of commerce, government officials, the program's administrators and faculty were able to establish key relationships within Costa Rica. Mr. Gonzalo Calderon, the Consul General of Costa Rica was instrumental in establishing contacts that would prove invaluable in the program's development. He facilitated meetings with government ministers and leading business executives including Mr. Armando Gonzales, managing editor of La Nacion and now officially an adjunct faculty member in the college. He provided introductions to officers of the Chamber of Industries, university administrators, hotel managers, business executives, administrators of international agencies and NGO's, and a touring company in Costa Rica that was instrumental in pulling together a variety of resources. 
Through meetings with the Consul General, a program was established which could be completed through a series of on-campus orientation meetings before the trip, lectures and visits while on the trip, and both pre- and postresearch, and presentations upon return to the United States.

It is the development of a mutually beneficial network that we believe has led to the success of the study abroad program. These relationships provide a wealth of information concerning the cultural, economic, and business environment of Costa Rica. Students participating in the study abroad program are exposed to some of the best speakers in the region. Students are also granted access to the most prestigious businesses in Costa Rica. In their time in the host country, students are provided a wealth of information from which they develop a rich case study of the cultural and economic factors in Costa Rica. We also realized that the relationship works to both parties' advantage (see Figure 1). In the process of creating a study abroad program, we established a reciprocating flow of information between from the university and parties in Costa Rica. The communication of information continued after the study abroad program when dignitaries from Costa Rica were invited to the university to deliver a series of presentations on the economic development in the region. Soon after, an exchange of faculty to teach topics at local universities and via the internet was proposed. Another surprising benefit of the relationship with partners in Costa Rica has been the bolstering of Southeastern's image with educational programs in other Latin American Countries. Southeastern now has become a host university to an association of Latin American Entrepreneurs that sends its members to Southeastern to study US business practices, has provided training for governmental entities and NGOs of several Latin American countries, and has partnered with a university in Honduras to establish an English language, dual degree program.

\section{COSTA RICA BUSINESS STUDY ABROAD PROGRAM FOR MBA STUDENTS}

Due to an increasingly negative impact on student credit hour production, lack of input on delivery and content, a concern for relevance, and a need to broaden both student and faculty horizons, Southeastern Louisiana University's College of Business and Technology moved away from an indirect enrollment study abroad program to create its own program for students. It was felt that a locally developed program that had significant faculty and administrative support would provide students with a relevant study abroad opportunity that would encourage learning, cross-cultural understanding and communication. In the development of the program for its students, the faculty emphasized the following characteristics:

- $\quad$ A multidisciplinary focus

- $\quad$ Emphasis on communication and understanding

- $\quad$ Leadership development

- $\quad$ Linkages to regional and international agencies

- $\quad$ An integrated, holistic conceptualization of international business \& development

As part of Southeastern Louisiana University's study abroad program, students attend a series of lectures on culture and rudimentary Spanish before traveling to the host country. The trip itself involves ten days in Costa Rica with visits to various educational, governmental, and business entities. Also included are meetings with business students at a Costa Rican university. These meetings between students generate interest among groups of students regarding careers in international business, cultural dynamics in business and economic development. The trip takes place during the intersession between spring and summer. Upon return from study abroad, students work in teams to prepare a detailed term paper on Costa Rican business and culture, and must make an oral presentation on their reports.

The program had only a handful of students attend in its first year. In its second year, twenty-four regular MBA and all nine of Southeastern's EMBA students participated in the program. During the second year, a special audience with the President of Costa Rica was granted. The President was gracious: holding a 45-minute discussion session with graduate students. A similar meeting between the First Lady of Costa Rica and female MBA students is in the works. The success of the study abroad program continues to generate increasing numbers of participants. Last year, a total of 47 students participated in the program. 


\section{BENEFITS AND OPPORTUNITIES FOR MBA STUDENTS}

The development of a global vision in the formation of human capital is the cornerstone that guarantees economic and social development, improves competitiveness, and strengthens democracy. Future business professionals will need to understand international business patterns and culture in order to successfully work in either the U.S.A. or abroad. Study abroad is a unique and excellent way to achieve cross-cultural awareness as well as to develop one's own personal and professional skills in operating in new and changing environments.

Understanding global strategies, international relations, and multicultural encounters is essential to a university education. Study abroad offers the opportunity to see other countries and savor other cultures first-hand while earning academic credits. Part of the mission of the College of Business and Technology is to prepare students to be leaders of business, industry, and government in a dynamic global environment. One of the ways the College has sought to fulfill this part of its mission is to offer students at both the graduate and the undergraduate levels a worldclass education that incorporates real business-world practices with an appreciation of cultural diversity and global competencies.

Through the Business Study Abroad Program, a comprehensive program offering opportunities to meet with people in a multinational setting including those who work with international government agencies, political officials and private business leaders is offered. This interaction is provided for through a working, learning, and problemsolving context, as opposed to simply being a tourist. Students are exposed to other countries and cultures in order to learn how business is conducted outside of the United States.

Giving students an advantage in today's competitive job market. Further, participants benefit by learning through experience. They will meet and interact with high-level business leaders of local and international businesses, and participate in corporate tours that will enrich their knowledge of Latin America and the world. Students benefit by participating in a system of dynamic and flexible apprenticeship where they have to work in groups and complete activities that enhance their cultural understanding and communication skills. By means of this program students increase their capacity for intercultural communication, increase their confidence in themselves, develop their analytic abilities, advance their maturity levels and improve their understanding of the world.

\section{SUMMARY AND CONCLUSION}

The internationalization of the economy, markets, and society point to major changes that must be addressed in education. In a changing and competitive education environment, it is important that faculty and students understand the role and implications of international business. In order to recognize the future of international business education, we need to be aware of the foundation of new paradigms and the incorporation of innovative educational systems in business schools worldwide. This is especially proper for business programs, where there is a need to facilitate students' learning with a rational view of how to conduct business overseas, and manage crosscultural communication and relationships. Ortiz (2004) recognizes the importance of a global mindset by faculty, staff and senior-level administrators in addressing the educational needs involved in the internationalization process.

For these reasons it is of vital importance to provide and rely on a system that allows business schools to initiate reform, and adequately address the global component in their curricula. Shetty and Rudell (2004) discuss the need for internationalization and the fact that such is not an option, but a necessity. Students need a quality study abroad program that will prepare them to be tomorrow's leaders in a rapidly changing business world that has global underpinnings.

Never has an international education been more important than today. Southeastern's College of Business and Technology is proud of the role its study abroad program plays in advancing its mission and preparing its students for tomorrow. The mission statement of the College of Business and Technology states that it will develop leaders able to compete in a global market. It was with this in mind that Southeastern pursued study abroad. Early on, students were encouraged to participate in other colleges' study abroad programs, and many students did. However, development of an in-house study abroad program addressed the concerns and shortcomings of piggybacking on the 
programs of others and provides students with experiences they will never forget. As one of the students who met with the President of Costa Rica said, "the study abroad program changed me forever."

\section{REFERENCES}

1. Altbach, P. G. (2002, spring). Perspectives on internationalizing higher education. Center for International Higher Education, Boston College, Boston, MA.

2. Brookefield, S. D. (1984). Self-directed adult learning: A critical paradigm. Adult Education Quarterly, 35(1), 59-71.

3. Hopkins, R. (1999). Studying abroad as a form of experiential education. Liberal Education, 85(3), 36-42.

4. $\quad$ Knowles, M. S. (1984). Androgogy in action. Jossey-Bass, San Francisco, CA.

5. Nadkarni, S. (2003). Instructional methods and mental models of students: An empirical investigation. Academy of Management Learning \& Education, 2(4), 335-352.

6. Ortiz, J. (2004). International business education in a global environment: A conceptual approach. International Education Journal, 5(2), 255-265.

7. Shetty, A. \& Rudell, F. (2004, November/December). Internationalizing the business program: A perspective of a small school. Journal of Education for Business, 78(20), 103-111.

8. Whetten, D. A. \& Clark, S. C. (1996). An integrated model for teaching management skills. Journal of Management Education, 20, 152-181.

\section{Figure1: Communication Between Colleges \& Universities And The International Community}

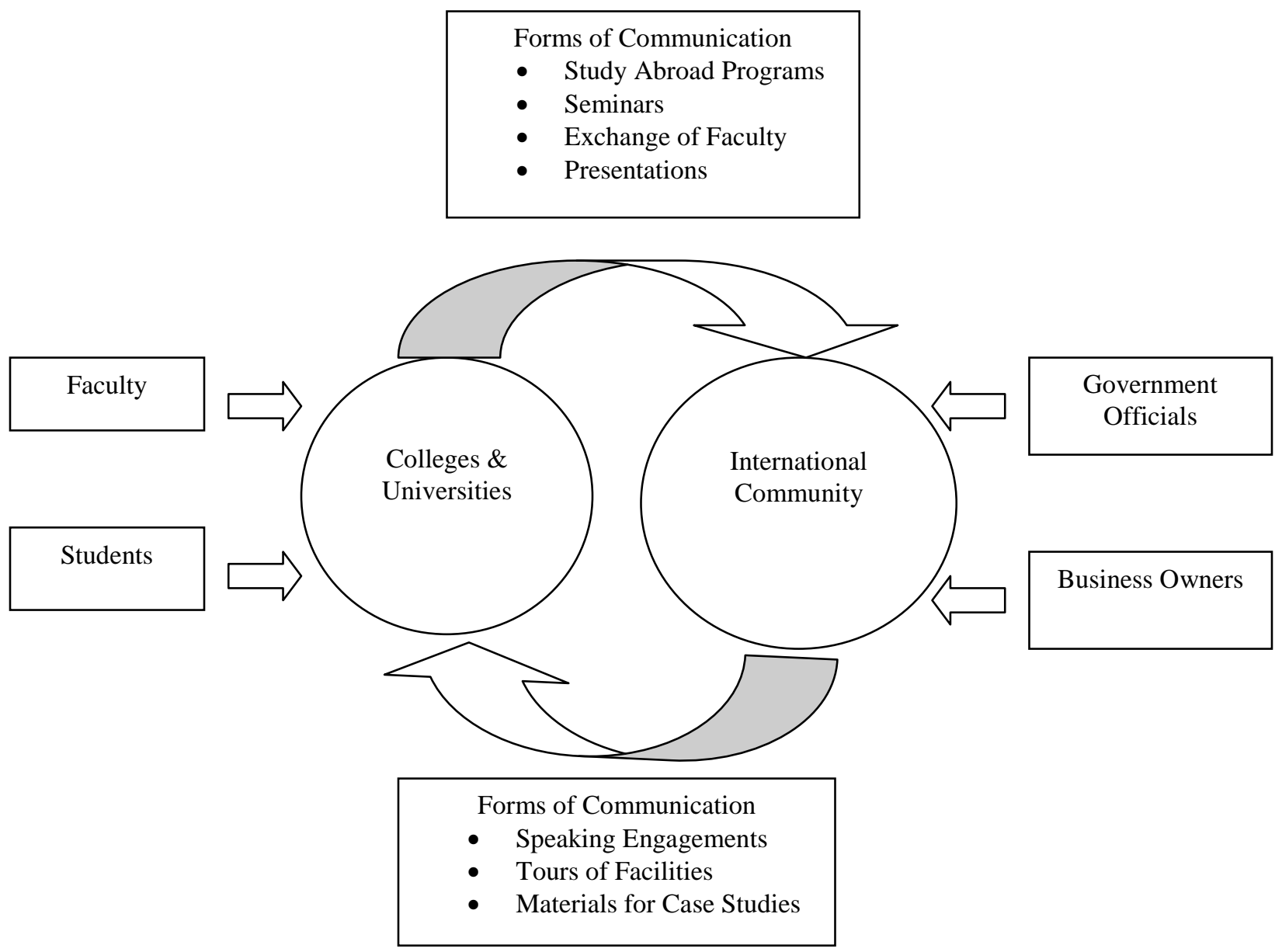

